\title{
AGRARIAN AND WETLAND AREAS UNDER METROPOLITAN THREATS: LEARNING FROM THE CASE OF INCIRALTI, IZMIR (TURKEY)
}

\author{
KARA, B. \\ Department of Landscape Architecture, Faculty of Agriculture, Aydin Adnan Menderes \\ University, 09970 Cakmar, Aydin, Turkey \\ (e-mail: bkara@adu.edu.tr; phone: +90-256-772-7022/1401; fax: +90-256-772-7233) \\ (Received $27^{\text {th }}$ Jun 2019; accepted $25^{\text {th }}$ Oct 2019)
}

\begin{abstract}
The aim of the study is to determine the Land use/land cover (LULC) changes and conversions in Inciralti İzmir (Turkey), and the fragmentation of these land uses between 1996 and 2018. Aerial photographs and Quickbird satellite imagery were used to obtain data. Aerial photographs were georectified using 1: 25,000 scaled topographic maps. The feature (vector) boundary of the study area was used to subset aerial photographs and Quickbird satellite image. LULC classes were defined according to Coordination of Information on the Environment (CORINE) LULC classes. The defined LULCs were digitized. Between 1996 and 2018, the highest conversion rate among agricultural areas occurred in permanently irrigated land with $41.43 \%$, and the highest conversion among wetlands were in inland marshes with 65.19\%. Between 1996 and 2018, the LULC with the highest increase in the number of patches was coastal lagoons with $300 \%$. Research data shows that there has been a great change, conversion and fragmentation process in construction sites, wetlands and agricultural areas in Inciralti between 1996 and 2018. Change, conversion, and fragmentation of LULCs have damaged the natural and cultural structure of Inciralti. In order to stop this damage, filling of wetlands and the construction on agricultural areas in Inciralti should be prevented.
\end{abstract}

Keywords: agricultural and wetland loss, Cakalburnu Lagoon, CORINE, LULC (land use/land cover) change, landscape fragmentation

\section{Introduction}

Human activities all over the world have been the dominant factor shaping most of the agricultural landscapes (Goudie and Viles, 1997) and wetlands (Moulton and Jacob, 2000). The most important reasons for the loss of agricultural areas and wetlands are population growth (Turner II, 1989; Hobbs et al., 1991) and rapid and unplanned urbanization (Lopez et al., 2001).

Urbanization directly affects fertile agricultural areas by transforming them into residential, commercial areas (Sanders, 2006), and it affects wetlands by transforming them into agricultural (Zhang et al., 2010), industrial and recreational areas and through filling works (Maynard and Wilcox, 1997). This conversion is called as Land use/land cover (LULC) change. One of the most important effects of rapid urbanization is fragmentation, which has a profound impact on urban ecosystems (Fan and Myint, 2014).

Land monitoring enables better using of land. It provides valuable information about the environment (Balado et al., 2018). Analyzing the change characteristics of LULC, revealing the evolution of different time scales are helpful to reveal the process under the influence of human society (Li et al., 2019). There are many ways to monitor or detect LULC change over time (Fonji and Taff, 2014). One of them is LULC mapping. Mapping LULC of large cities is a main component of detecting rapid changes (RujoiuMare and Mihai, 2016; Nuthammachot and Stratoulias, 2019). 
Coordination of Information on the Environment (CORINE) is widely used in LULC mapping. CORINE is the longest available land cover and land cover change database with a consistent class labeling system (Cole et al., 2018). CORINE data sets are useful for describing long term structural changes of ecological complexes (Petrişor et al., 2014). CORINE database is a key for integrated environmental assessment (Dzieszko, 2014).

Urbanization, which has been encouraged by remarkable economic development, has progressed increasingly rapidly in Turkey in the last fifty years. In the industrialization and urbanization processes, it is clearly documented that large agricultural areas have been lost due to non-agricultural uses (Esbah, 2004). Metropolitan areas now cover an important part of Turkey's agriculture. Wetlands are among the most threatened ecosystems of Turkey.

Several studies using Remote Sensing (RS) and Geographical Information Systems (GIS) techniques in Turkey have been conducted to examine the intense pressure of the urbanization on agricultural lands and wetlands and to determine LULC changes.

In a study conducted in Antakya, the Amik plain, one of the most fertile plains of Turkey, was determined to be under the intense pressure of the expansion of urban and industrial areas (Kilic et al., 2005).

LULC changes in the coastal region of the Çandarlı Bay between 1990 and 2005 were examined in terms of the conversion of agricultural areas, olive groves and coastal wetlands into urban areas (Kesgin and Nurlu, 2009).

In the study on the LULC changes in the urban settlement of Kuşadası district between the years 1993 and 2006, it was determined that agricultural areas decreased and were converted into industrial, commercial and residential areas (Kara et al., 2013).

The study area is Inciralti located in the metropolitan area of Izmir, the third largest city of Turkey. The reason for choosing Inciralti as the study area is that it is home to two important ecosystems such as fertile agricultural land and wetlands at the same time in the center of the metropolitan area of Izmir.

The aim of a study is to monitor the changes/conversions and fragmentations in agricultural areas and wetlands in Inciralti in the period of 22 years between 1996 and 2018 by using aerial photographs, satellite image, RS and GIS techniques.

\section{Materials and methods}

\section{Study area}

Inciralti, which is the study area, is located on the west coast of Turkey, in the Aegean region, in the south of the Izmir bay, and in the metropolitan area of Izmir, the third largest city, within the boundaries of Balcova district (Fig. 1). Coordinates of Inciralti are $38^{\circ} 24^{\prime} 42.28^{\prime \prime} \mathrm{N} 27^{\circ} 1^{\prime} 58.47^{\prime \prime} \mathrm{E}$ and $38^{\circ} 23^{\prime} 55.76^{\prime} \mathrm{N} 27^{\circ} 3^{\prime} 46.64^{\prime \prime} \mathrm{E}$. Its surface area is 378.04 ha. Within the boundaries of the study area, there are the Balcova plain and Cakalburnu lagoon, which are among the most fertile agricultural areas and wetlands of the city (Fig. 2).

Inciralti is the only area that has been able to maintain its agricultural character despite the intensive urbanization in the metropolitan area of Izmir. In the Balcova plain, there is a very intensive production in greenhouses, open fields, flower, vegetable, citrus gardens and various orchards.

Cakalburnu lagoon, which is one of the most important natural areas of Izmir, is a wetland area integrated with the city, unlike other wetlands. Cakalburnu lagoon is one 
of the important wetlands in Izmir with 103 bird species (Sevil, 2010). The world-wide endangered Pelecanus crispus (Dalmatian Pelican) and Hoplopterus spinosus (Spurwinged Lapwing) that breeds only in Greece also breed only in Cakalburnu lagoon in Turkey. Cakalburnu lagoon is one of the areas where Tapes decussatus (Grooved carpet Shell), a mussel species of economic value, is commercially collected in Turkey (Serdar et al., 2010). The predominant vegetation of Cakalburnu lagoon is composed of Salicornia europaea L. (Common glasswort).

In addition to its agricultural potential and ecological value, Inciralti is the only green area in Izmir as the "last coast with accessible recreational potential for all.

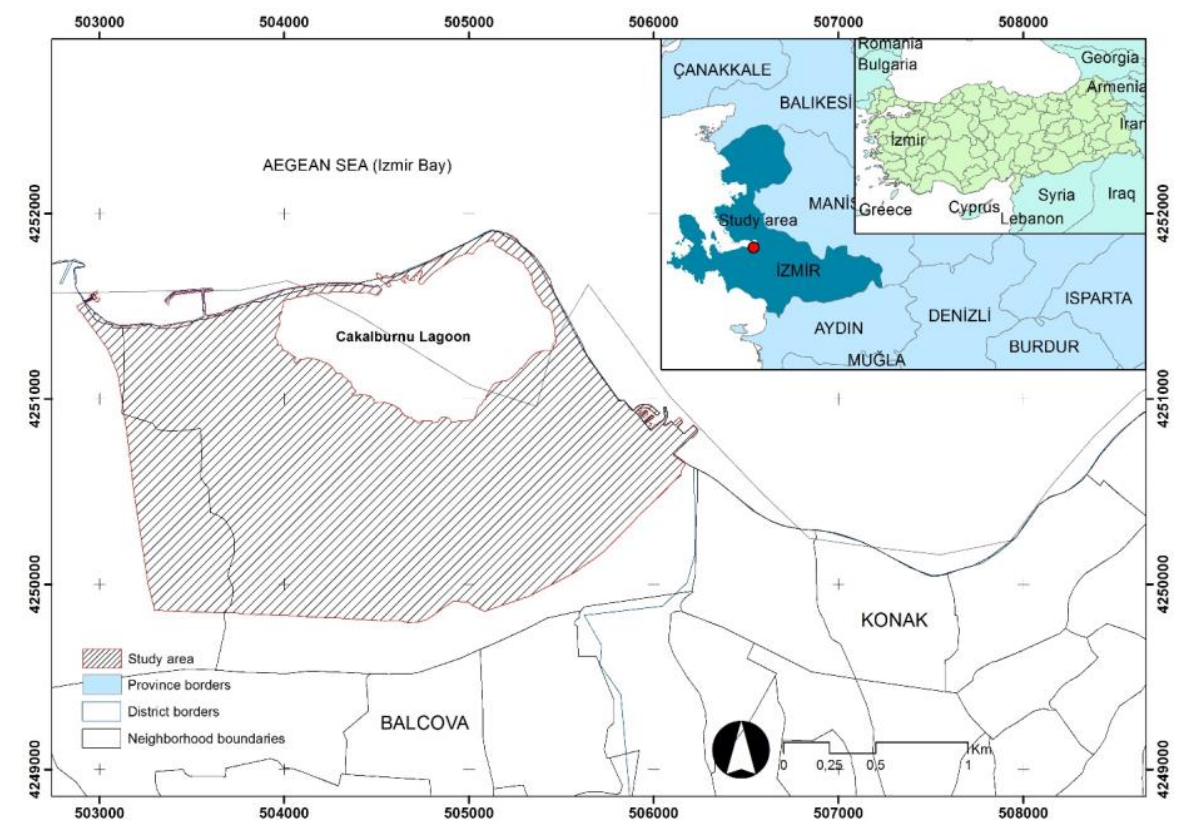

Figure 1. Location of the study area

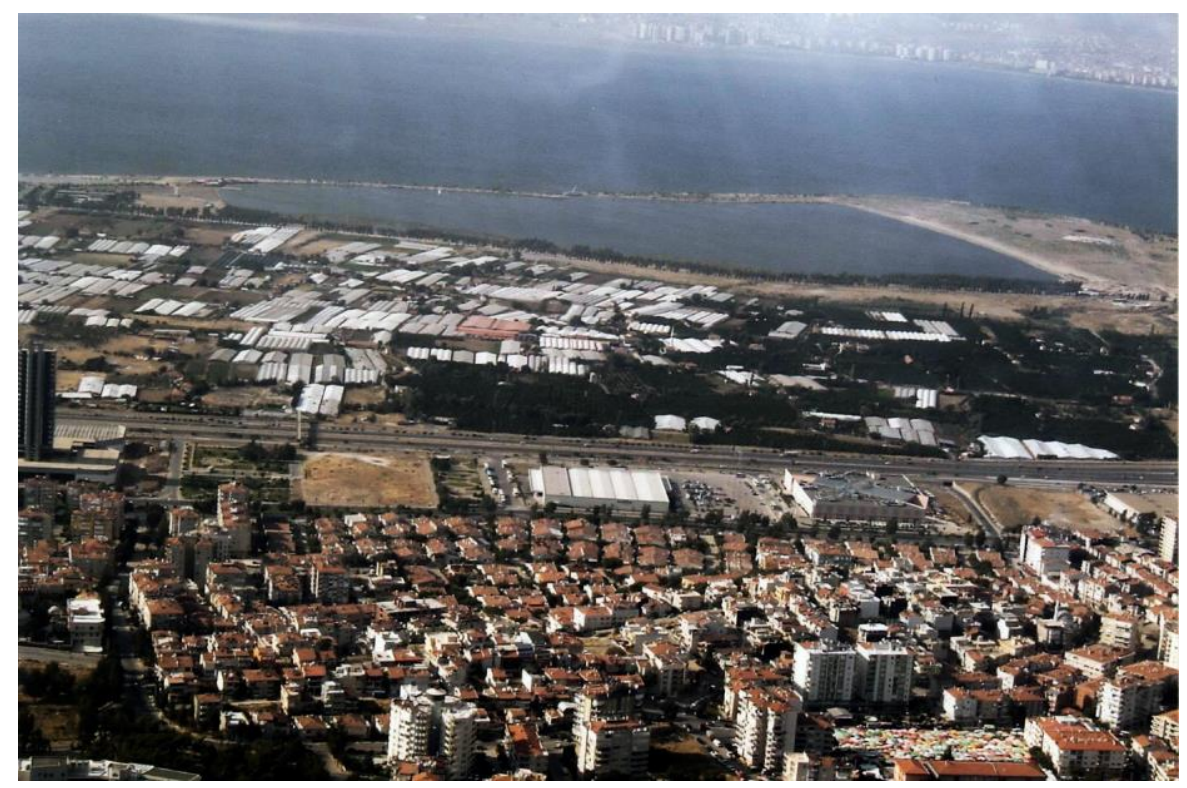

Figure 2. Inciralti with fertile agricultural areas and wetland lies on the north of Balcova urban area 


\section{Data collection}

The main material of the study consists of aerial photographs and satellite image. Aerial photographs and QuickBird satellite image were used to obtain LULC data for the previous years in the study area. The aerial photographs are monochrome monoscopic/stereoscopic with a 1/35.000 scale belonging to the year 1996. Highresolution QuicBird satellite image has a spatial resolution of 0.6-m dated June 25, 2018. ERDAS IMAGINE® 9.2 and Esri ${ }^{\circledR}$ ArcMap 9.3 software were used to process digital data. RS and GIS techniques were used to detect the LULC changes and conversions.

\section{Image pre-processing}

The geometric rectification of the aerial photographs was made according to the topographic map with a 1:25,000 scale. Satellite image and digitized aerial photographs were georectified in the Universal Transverse Mercator (UTM) (Zone 35) coordinate system using first-order polynomial transformation and subsetted according to the feature (vector) boundary of the study area.

\section{Interpretation of aerial photographs and satellite image}

Visual interpretation and on-screen digitizing method were used to detect the LULC changes and conversions between 1996 and 2018. Aerial photographs and satellite image were visually interpreted on the screen using direct (tone, texture, shape, and pattern) and indirect (location and relationship) identification elements.

\section{Image classification}

LULC changes and conversions were detected by using remotely sensed data. The bitemporal change detection technique (Royer and Charbonneau, 1988) was used to determine LULC changes and conversions from 1996 to 2018. CORINE Land Cover nomenclature was used in change detection.

The cross-tabulation method was used to determine LULC changes. In this way, a change matrix was produced (Wang et al., 2006).

In the study area, 16 CORINE LULC classes were determined at Level 3 (Table 1).

\section{Data processing}

A comparison between 1996 and 2018 of the field data were generated. Then, the quantitative data of changes, increases, and losses in the LULC of each category were compiled. Thus, the expansion of urban sprawl on agricultural areas and wetlands was determined.

The digitization process not only provided an analysis of the changes in the total area of LULCs but also produced quantitative information on the rate of fragmentation of the parcels and changes in the average parcel size.

\section{Results}

Between 1996 and 2018, there were serious changes in LULC in Inciralti (Figs. 3 and 4; Table 2). In 1996, coastal lagoons, covering the $19.04 \%$ of the area, constituted the largest LULC of Inciralti. In 2018, coastal lagoons became the third largest LULC with a ratio of $13.32 \%$. 
Table 1. CORINE LULC classes used in the study

\begin{tabular}{|c|c|c|c|}
\hline No. & $\begin{array}{l}\text { CORINE } \\
\text { classes }\end{array}$ & LULC & Description \\
\hline 1 & 112 & Discontinuous urban fabric & Urban fabric \\
\hline 2 & 121 & Industrial or commercial units & \multirow{3}{*}{ Industrial, commercial and transport units } \\
\hline 3 & 122 & Road and rail networks and associated land & \\
\hline 4 & 123 & Port areas & \\
\hline 5 & 132 & Dump sites & \multirow{2}{*}{ Mine, dump and construction sites } \\
\hline 6 & 133 & Construction sites & \\
\hline 7 & 141 & Green urban areas & \multirow{2}{*}{ Artificial, non-agricultural vegetated areas } \\
\hline 8 & 142 & Sport and leisure facilities & \\
\hline 9 & 211 & Non-irrigated arable land & \multirow{2}{*}{ Arable land } \\
\hline 10 & 212 & Permanently irrigated land & \\
\hline 11 & 222 & Fruit trees and berry plantations & Permanent crops \\
\hline 12 & 323 & Sclerophyllous vegetation & Scrub and/or herbaceous vegetation associations \\
\hline 13 & 333 & Sparsely vegetated areas & Open spaces with little or no vegetation \\
\hline 14 & 411 & Inland marshes & Inland wetlands \\
\hline 15 & 511 & Water courses & Inland waters \\
\hline 16 & 521 & Coastal lagoons & Marine waters \\
\hline
\end{tabular}

CORINE $=$ coordination of information on the environment, LULC $=$ land use and land cove

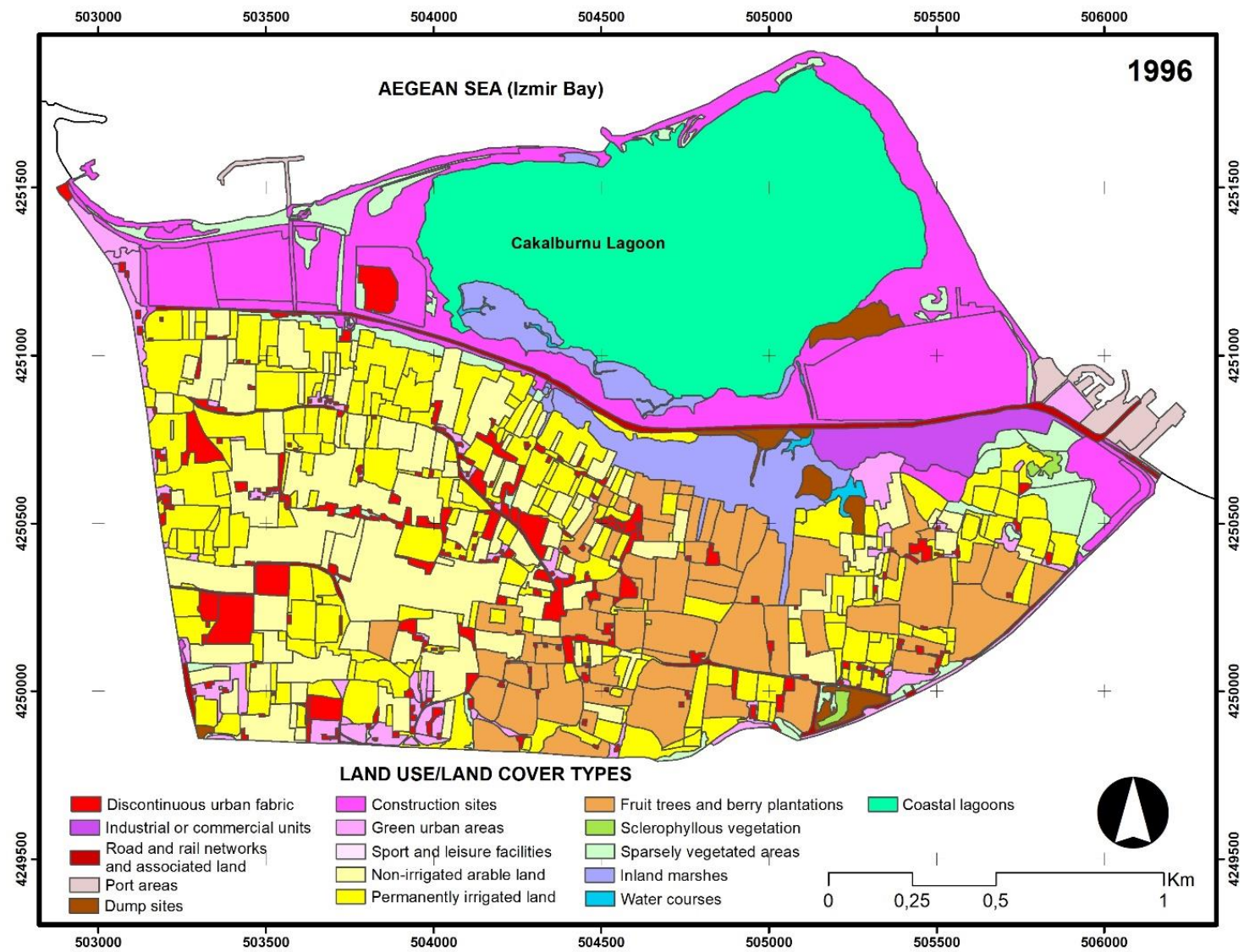

Figure 3. LULC sizes in 1996 


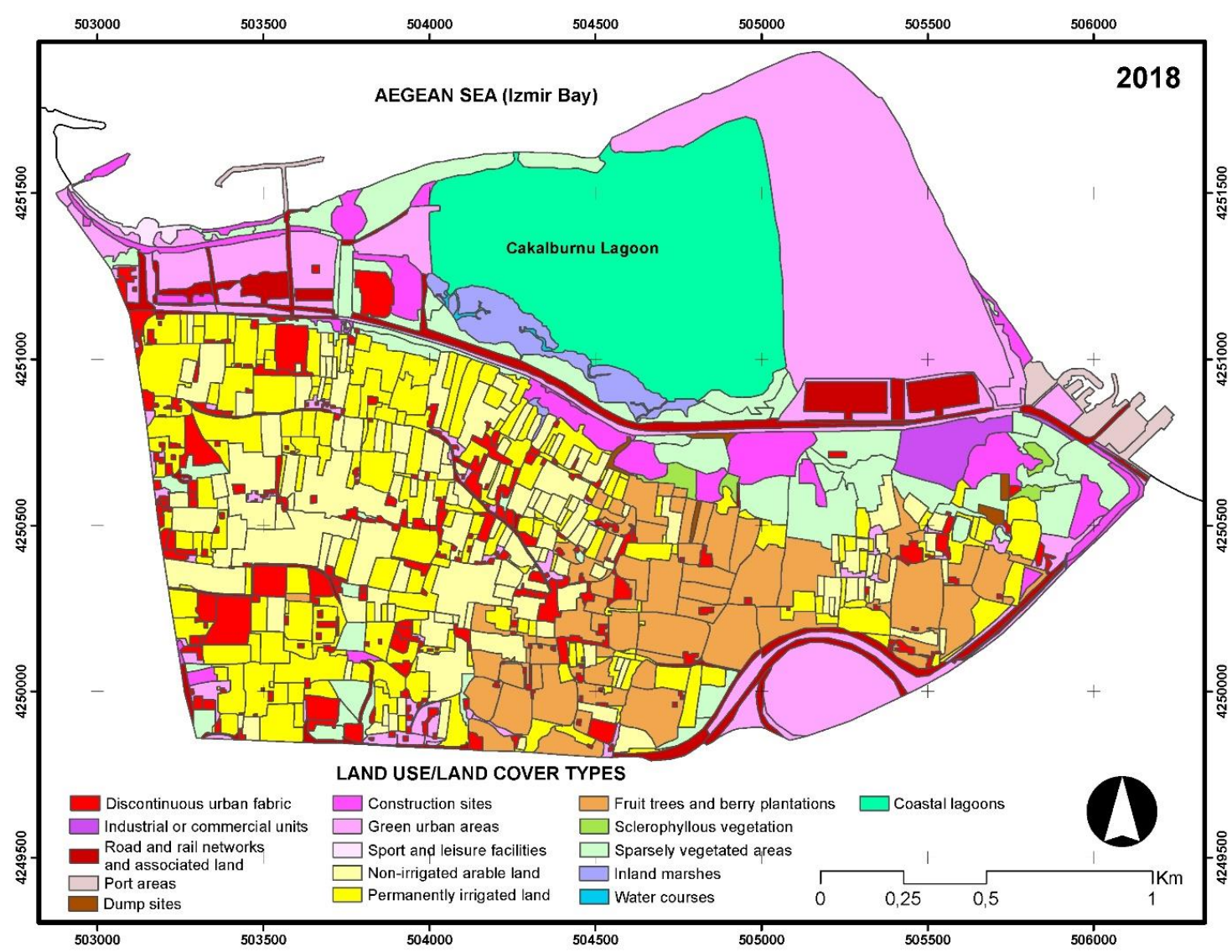

Figure 4. LULC sizes in 2018

Table 2. LULC Changes in Inciralti between 1996 and 2018

\begin{tabular}{c|c|c|c|c|c|c}
\hline \multirow{2}{*}{ No. } & \multicolumn{7}{|c}{ Area } \\
\cline { 2 - 7 } & \multicolumn{2}{|c|}{$\mathbf{1 9 9 6}$} & \multicolumn{2}{c}{$\mathbf{2 0 1 8}$} & \multicolumn{2}{c}{ Image difference } \\
\cline { 2 - 7 } 1 & ha & \% & ha & \% & ha & \% \\
2 & 19.30 & 4.13 & 25.78 & 5.52 & 6.47 & 25.11 \\
3 & 7.39 & 1.58 & 4.55 & 0.97 & -2.83 & -62.25 \\
4 & 6.29 & 1.35 & 21.38 & 4.57 & 15.09 & 70.58 \\
5 & 5.23 & 1.12 & 5.23 & 1.12 & 0.00 & 0.00 \\
6 & 5.24 & 1.12 & 1.12 & 0.24 & -4.13 & -369.01 \\
7 & 72.13 & 15.44 & 19.20 & 4.11 & -52.93 & -275.67 \\
8 & 14.45 & 3.09 & 89.88 & 19.24 & 75.43 & 83.92 \\
9 & 0.00 & 0.00 & 0.87 & 0.19 & 0.87 & 100.00 \\
10 & 68.58 & 14.68 & 58.70 & 12.56 & -9.88 & -16.84 \\
11 & 82.61 & 17.68 & 73.63 & 15.76 & -8.98 & -12.19 \\
12 & 58.25 & 12.47 & 50.75 & 10.86 & -7.50 & -14.78 \\
13 & 0.87 & 0.19 & 1.82 & 0.39 & 0.95 & 52.26 \\
14 & 16.48 & 3.53 & 44.07 & 9.43 & 27.59 & 62.61 \\
15 & 20.15 & 4.31 & 7.54 & 1.61 & -12.62 & -167.41 \\
16 & 1.31 & 0.28 & 0.52 & 0.11 & -0.79 & -151.45 \\
Total & 88.97 & 19.04 & 62.22 & 13.32 & -26.75 & -42.99 \\
\hline
\end{tabular}


The second largest area among LULCs in 1996 (17.68\% of the total) was the permanently irrigated land, which is the western part of the study area. The majority of permanently irrigated land consists of the areas where vegetables are cultivated. In 2018, the permanently irrigated land occupied less area compared to 1996 but was the second largest area (15.76\% of the total).

The LULC with the third largest area in 1996 (15.44\%) was the construction sites. A large part of the construction sites consists of fillings (rubble dumping) made in the northern part of the area on Izmir Bay coast and Cakalburnu lagoon. In 2018, the construction sites accounted for $4.11 \%$ of the total area and ranked ninth in terms of area size.

The discontinuous urban fabric ranked seventh in terms of area size among LULCs $(4.13 \%)$ in 1996. The discontinuous urban fabric consists of agricultural enterprises and luxury villas in the central and western part of the area. The area covered by the discontinuous urban fabric increased to $5.52 \%$ but remained in the seventh place in 2018 .

Between 1996 and 2018, the most significant increase in the LULC in terms of area size was in sport and leisure facilities $(100 \%)$, green urban areas $(83.92 \%)$, road and rail networks and associated land (70.58\%). The most significant decrease was in dump sites $(369.01 \%)$, construction sites $(275.67 \%)$, and inland marshes $(167.41 \%)$.

Tables 3 and 4 show the changes and conversions between LULCs. The discontinuous urban fabric increased by 25.11\% (6.47 ha). Between 1996 and 2018, the city developed on the $8.22 \%$ (1.19 ha) of green urban areas, 5.99\% (4.95 ha) of permanently irrigated land, $3.16 \%$ (2.17 ha) of non-irrigated arable land and $1.07 \%$ (0.62 ha) of fruit trees and berry plantations (Fig. 5).
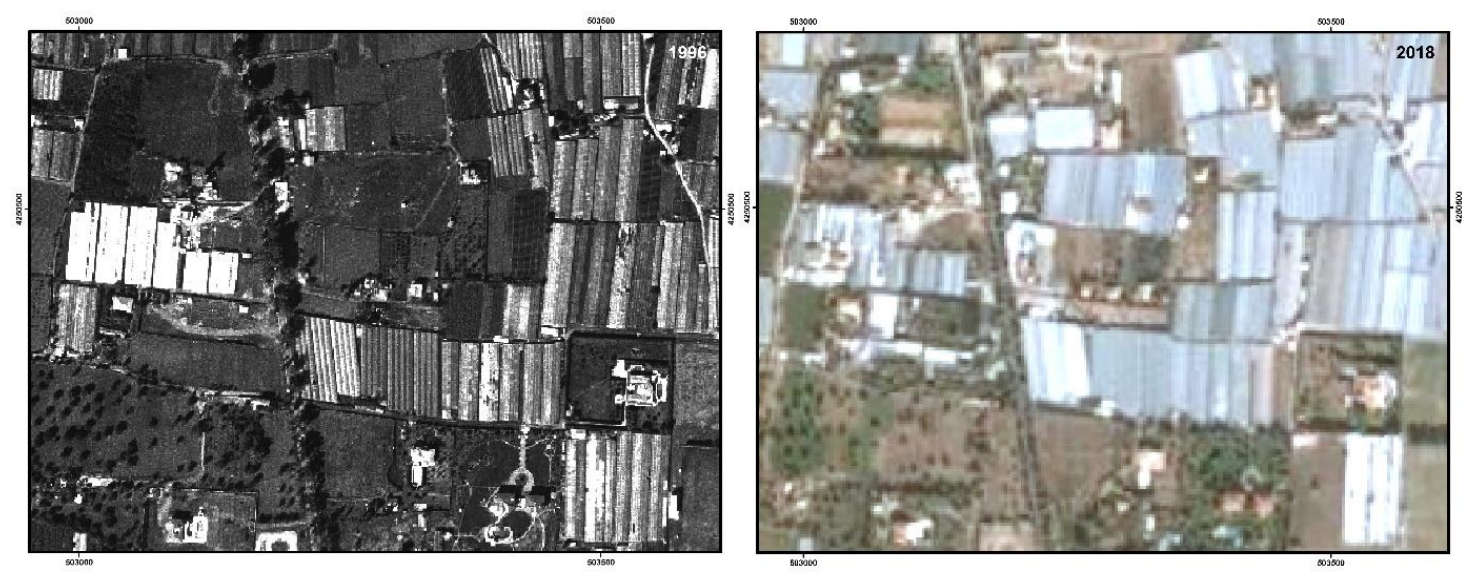

Figure 5. The spread of the discontinuous urban fabric to the non-irrigated arable land and permanently irrigated land

Green urban areas increased by $83.92 \%$ (75.43 ha). The most important reason for the increase in green urban areas is the conversion of $54.32 \%$ (2.85 ha) of the dump sites, $50.69 \%$ (36.56 ha) of construction sites and $29.14 \%$ (25.92 ha) of coastal lagoons into green urban areas.

The non-irrigated arable land (greenhouse cultivation) showed a decrease of $-16.84 \%$ (9.88 ha). $26.30 \%$ (18.04 ha) of the non-irrigated arable land was converted into permanently irrigated land, $3.16 \%$ (2.17 ha) into the discontinuous urban fabric, and $1.86 \%$ (1.28 ha) into green urban areas. 
Table 3. The conversion matrix of LULC change from 1996 to 2018 (\%)

\begin{tabular}{|c|c|c|c|c|c|c|c|c|c|c|c|c|c|c|c|c|}
\hline \multirow{3}{*}{ LULC in 2018} & \multicolumn{16}{|c|}{ LULC class changes (\%) } \\
\hline & \multicolumn{16}{|c|}{ LULC in 1996} \\
\hline & 1 & 2 & 3 & 4 & 5 & 6 & 7 & 8 & 9 & 10 & 11 & 12 & 13 & 14 & 15 & 16 \\
\hline 1 & 85.49 & 1.27 & 0.00 & 0.00 & 0.00 & 0.18 & 8.22 & 0.00 & 3.16 & 5.99 & 1.07 & 0.00 & 0.74 & 0.00 & 0.00 & 0.00 \\
\hline 2 & 0.00 & 54.64 & 0.00 & 0.00 & 0.00 & 0.72 & 0.00 & 0.00 & 0.00 & 0.00 & 0.00 & 0.00 & 0.00 & 0.00 & 0.00 & 0.00 \\
\hline 3 & 1.36 & 0.00 & 50.82 & 0.00 & 0.00 & 17.72 & 3.29 & 0.00 & 0.25 & 2.79 & 2.82 & 0.00 & 3.03 & 0.25 & 0.00 & 0.00 \\
\hline 4 & 0.00 & 0.00 & 0.00 & 100.00 & 0.00 & 0.00 & 0.00 & 0.00 & 0.00 & 0.00 & 0.00 & 0.00 & 0.00 & 0.00 & 0.00 & 0.00 \\
\hline 5 & 0.00 & 0.00 & 0.00 & 0.00 & 3.75 & 0.00 & 0.00 & 0.00 & 0.00 & 0.60 & 0.00 & 0.00 & 0.00 & 2.12 & 0.00 & 0.00 \\
\hline 6 & 0.00 & 2.04 & 0.00 & 0.00 & 21.64 & 9.86 & 0.75 & 0.00 & 0.51 & 2.05 & 0.45 & 0.00 & 15.31 & 27.23 & 22.69 & 0.10 \\
\hline 7 & 4.54 & 1.90 & 48.17 & 0.00 & 54.32 & 50.69 & 60.11 & 0.00 & 1.86 & 4.91 & 4.57 & 46.38 & 20.16 & 0.00 & 7.41 & 29.14 \\
\hline 8 & 0.00 & 0.00 & 0.00 & 0.00 & 0.00 & 1.04 & 0.00 & 0.00 & 0.00 & 0.00 & 0.00 & 0.00 & 0.69 & 0.00 & 0.00 & 0.00 \\
\hline 9 & 2.28 & 0.00 & 0.00 & 0.00 & 0.00 & 0.00 & 1.81 & 0.00 & 66.39 & 14.28 & 1.01 & 0.00 & 0.47 & 0.00 & 0.00 & 0.00 \\
\hline 10 & 2.70 & 0.00 & 0.48 & 0.00 & 0.00 & 0.00 & 9.11 & 0.00 & 26.30 & 58.57 & 7.07 & 0.00 & 2.24 & 4.23 & 0.00 & 0.00 \\
\hline 11 & 1.98 & 0.00 & 0.00 & 0.00 & 0.00 & 0.00 & 0.00 & 0.00 & 0.23 & 2.73 & 81.77 & 0.00 & 0.00 & 1.59 & 0.00 & 0.00 \\
\hline 12 & 0.00 & 0.00 & 0.00 & 0.00 & 0.00 & 0.00 & 0.00 & 0.00 & 0.00 & 0.00 & 0.00 & 25.63 & 3.19 & 5.34 & 0.00 & 0.00 \\
\hline 13 & 1.65 & 40.15 & 0.53 & 0.00 & 20.29 & 19.37 & 16.70 & 0.00 & 1.30 & 8.08 & 1.24 & 27.99 & 53.60 & 24.43 & 35.44 & 0.62 \\
\hline 14 & 0.00 & 0.00 & 0.00 & 0.00 & 0.00 & 0.00 & 0.00 & 0.00 & 0.00 & 0.00 & 0.00 & 0.00 & 0.29 & 34.81 & 0.00 & 0.53 \\
\hline 15 & 0.00 & 0.00 & 0.00 & 0.00 & 0.00 & 0.00 & 0.00 & 0.00 & 0.00 & 0.00 & 0.00 & 0.00 & 0.00 & 0.00 & 34.46 & 0.08 \\
\hline 16 & 0.00 & 0.00 & 0.00 & 0.00 & 0.00 & 0.43 & 0.00 & 0.00 & 0.00 & 0.00 & 0.00 & 0.00 & 0.31 & 0.00 & 0.00 & 69.53 \\
\hline 1996 total & 100.00 & 100.00 & 100.00 & 100.00 & 100.00 & 100.00 & 100.00 & 0.00 & 100.00 & 100.00 & 100.00 & 100.00 & 100.00 & 100.00 & 100.00 & 100.00 \\
\hline Class changes & 14.51 & 45.36 & 49.18 & 0.00 & 96.25 & 90.14 & 39.89 & 0.00 & 33.61 & 41.43 & 18.23 & 74.37 & 46.40 & 65.19 & 65.54 & 30.47 \\
\hline Image difference & 25.11 & -62.25 & 70.58 & 0.00 & -369.01 & -275.67 & 83.92 & 100.00 & -16.84 & -12.19 & -14.78 & 52.26 & 62.61 & -167.41 & -151.45 & -42.99 \\
\hline
\end{tabular}

LULC = land use and land cover. 1. discontinuous urban fabric; 2. industrial or commercial units; 3. road and rail networks and associated land; 4. port areas; 5. dump sites; 6. construction sites; 7. green urban areas; 8. sport and leisure facilities; 9. non-irrigated arable land; 10. permanently irrigated land; 11. fruit trees and berry plantations; 12 . sclerophyllous vegetation; 13 . sparsely vegetated areas; 14 . inland marshes; 15 . water courses; 16 . coastal lagoons 
Table 4. The conversion matrix of LULC change from 1996 to 2018 (ha)

\begin{tabular}{|c|c|c|c|c|c|c|c|c|c|c|c|c|c|c|c|c|c|}
\hline \multirow{3}{*}{ LULC in 2018} & \multicolumn{17}{|c|}{ LULC class changes (ha) } \\
\hline & \multicolumn{17}{|c|}{ LULC in 1996} \\
\hline & 1 & 2 & 3 & 4 & 5 & 6 & 7 & 8 & 9 & 10 & 11 & 12 & 13 & 14 & 15 & 16 & 2018 total \\
\hline 1 & 16.50 & 0.09 & 0.00 & 0.00 & 0.00 & 0.13 & 1.19 & 0.00 & 2.17 & 4.95 & 0.62 & 0.00 & 0.12 & 0.00 & 0.00 & 0.00 & 25.78 \\
\hline 2 & 0.00 & 4.04 & 0.00 & 0.00 & 0.00 & 0.52 & 0.00 & 0.00 & 0.00 & 0.00 & 0.00 & 0.00 & 0.00 & 0.00 & 0.00 & 0.00 & 4.55 \\
\hline 3 & 0.26 & 0.00 & 3.20 & 0.00 & 0.00 & 12.78 & 0.48 & 0.00 & 0.17 & 2.30 & 1.64 & 0.00 & 0.50 & 0.05 & 0.00 & 0.00 & 21.38 \\
\hline 4 & 0.00 & 0.00 & 0.00 & 5.23 & 0.00 & 0.00 & 0.00 & 0.00 & 0.00 & 0.00 & 0.00 & 0.00 & 0.00 & 0.00 & 0.00 & 0.00 & 5.23 \\
\hline 5 & 0.00 & 0.00 & 0.00 & 0.00 & 0.20 & 0.00 & 0.00 & 0.00 & 0.00 & 0.49 & 0.00 & 0.00 & 0.00 & 0.43 & 0.00 & 0.00 & 1.12 \\
\hline 6 & 0.00 & 0.15 & 0.00 & 0.00 & 1.13 & 7.11 & 0.11 & 0.00 & 0.35 & 1.69 & 0.26 & 0.00 & 2.52 & 5.49 & 0.30 & 0.09 & 19.20 \\
\hline 7 & 0.88 & 0.14 & 3.03 & 0.00 & 2.85 & 36.56 & 8.69 & 0.00 & 1.28 & 4.05 & 2.66 & 0.40 & 3.32 & 0.00 & 0.10 & 25.92 & 89.88 \\
\hline 8 & 0.00 & 0.00 & 0.00 & 0.00 & 0.00 & 0.75 & 0.00 & 0.00 & 0.00 & 0.00 & 0.00 & 0.00 & 0.11 & 0.00 & 0.00 & 0.00 & 0.87 \\
\hline 9 & 0.44 & 0.00 & 0.00 & 0.00 & 0.00 & 0.00 & 0.26 & 0.00 & 45.53 & 11.80 & 0.59 & 0.00 & 0.08 & 0.00 & 0.00 & 0.00 & 58.70 \\
\hline 10 & 0.52 & 0.00 & 0.03 & 0.00 & 0.00 & 0.00 & 1.32 & 0.00 & 18.04 & 48.38 & 4.12 & 0.00 & 0.37 & 0.85 & 0.00 & 0.00 & 73.63 \\
\hline 11 & 0.38 & 0.00 & 0.00 & 0.00 & 0.00 & 0.00 & 0.00 & 0.00 & 0.15 & 2.26 & 47.63 & 0.00 & 0.00 & 0.32 & 0.00 & 0.00 & 50.75 \\
\hline 12 & 0.00 & 0.00 & 0.00 & 0.00 & 0.00 & 0.00 & 0.00 & 0.00 & 0.00 & 0.00 & 0.00 & 0.22 & 0.52 & 1.08 & 0.00 & 0.00 & 1.82 \\
\hline 13 & 0.32 & 2.97 & 0.03 & 0.00 & 1.06 & 13.97 & 2.41 & 0.00 & 0.89 & 6.67 & 0.72 & 0.24 & 8.83 & 4.92 & 0.46 & 0.55 & 44.07 \\
\hline 14 & 0.00 & 0.00 & 0.00 & 0.00 & 0.00 & 0.00 & 0.00 & 0.00 & 0.00 & 0.00 & 0.00 & 0.00 & 0.05 & 7.01 & 0.00 & 0.47 & 7.54 \\
\hline 15 & 0.00 & 0.00 & 0.00 & 0.00 & 0.00 & 0.00 & 0.00 & 0.00 & 0.00 & 0.00 & 0.00 & 0.00 & 0.00 & 0.00 & 0.45 & 0.07 & 0.52 \\
\hline 16 & 0.00 & 0.00 & 0.00 & 0.00 & 0.00 & 0.31 & 0.00 & 0.00 & 0.00 & 0.00 & 0.00 & 0.00 & 0.05 & 0.00 & 0.00 & 61.86 & 62.22 \\
\hline 1996 total & 19.30 & 7.39 & 6.29 & 5.23 & 5.24 & 72.13 & 14.45 & 0.00 & 68.58 & 82.61 & 58.25 & 0.87 & 16.48 & 20.15 & 1.31 & 88.97 & 467.25 \\
\hline Class changes & 2.80 & 3.35 & 3.09 & 0.00 & 5.05 & 65.02 & 5.76 & 0.00 & 23.05 & 34.22 & 10.62 & 0.65 & 7.65 & 13.14 & 0.86 & 27.11 & \\
\hline Image difference & 6.47 & -2.83 & 15.09 & 0.00 & -4.13 & -52.93 & 75.43 & 0.87 & -9.88 & -8.98 & -7.50 & 0.95 & 27.59 & -12.62 & -0.79 & -26.75 & \\
\hline
\end{tabular}

LULC = land use and land cover. 1. discontinuous urban fabric; 2. industrial or commercial units; 3. road and rail networks and associated land; 4. port areas; 5. dump sites; 6. construction sites; 7. green urban areas; 8. sport and leisure facilities; 9. non-irrigated arable land; 10. permanently irrigated land; 11. fruit trees and berry plantations; 12. sclerophyllous vegetation; 13. sparsely vegetated areas; 14 . inland marshes; 15 . water courses; 16. coastal lagoons 
Inland marshes showed a significant decrease of $-167.41 \%$ (12.62 ha). Upon looking at the conversion matrix, the main reason for the change in these areas is the conversion of $27.23 \%$ (5.49 ha) into construction sites, $24.43 \%$ (4.92 ha) into sparsely vegetated areas and $5.34 \%$ (1.08 ha) into sclerophyllous vegetation.

Coastal lagoons showed a decrease of $-42.99 \%$ (26.75 ha). $29.14 \%$ (25.92 ha) of coastal lagoons were converted into green urban areas (Fig. 6).

Between 1996 and 2018, there were significant changes in the patch numbers and patch areas of the LULC categories (Table 5). Between these years, the total patch number of the discontinuous urban fabric increased by $24.12 \%$ (from 199 to 247). The highest increase in the patch number was in the area with a 0-0.9 ha patch size (23.86\%/from 197 to 244). There was no change in the average patch area size of the discontinuous urban fabric ( 0.1 ha).

The total patch number of green urban areas increased from 65 to 76 (an increase of $16.92 \%)$. The highest increase (300\%/from 3 to 9) was observed in the patches of 1 4.9 ha. The average patch area increased by $536.36 \%$ from 0.22 ha 1.18 ha.

The total patch number of the non-irrigated arable land increased by $30.77 \%$ from 104 to 136. The highest increase in the patch number was in the patch group of 0-0.9 ha with $44.19 \%$ (from 86 to 124). The average patch area size of the non-irrigated arable land decreased by $34.85 \%$ (from 0.66 to 0.43 ha).

The total patch number of inland marshes decreased by $58.33 \%$ from 12 to 5 . The highest decrease in the patch number was in the areas with a patch size of 0-0.9 ha (60\%/from 10 to 4$)$. The average patch area decreased by $10.12 \%$ from 1.68 ha to 1.51 ha.

The total patch number of coastal lagoons increased by $300 \%$ (from 1 to 3 ). The highest increase in the patch number was in the areas with a patch size of 0-0.9 (200\%/from 0 to 2). The average patch area decreased by $76.69 \%$ (from 88.97 ha to $20.74 \mathrm{ha}$ ).

\section{Discussion}

The effects of urbanization in Inciralti are observed with the conversion of different LULCs into urban areas. The conversion of agricultural areas (permanently irrigated land, non-irrigated arable land, and fruit trees and berry plantations) into urban areas (discontinuous urban fabric) shows that urbanization in Inciralti creates great pressure on agricultural areas. This result is line with results of a previous survey in Nanping city, China, where the pressure of urban expansion on agricultural areas can be seen as decreases in cultivated land (Fan and Zhao, 2019). An indirect indicator of the continuation of a process leading to the construction of Inciralti is that agricultural areas were left unused. The decrease in the importance given to agriculture has led to the large abandonment of agricultural areas (Price et al., 2015).

Although the impact of human activities is for all natural ecosystems, it particularly affects coastal wetlands (Valdez et al., 2016). The reason for the conversion of wetlands into urban and agricultural areas in Inciralti is the filling of the area with rubble and garbage. As a result of filling Cakalburnu lagoon with rubble, Inciralti has been losing its wetlands characteristics. The reason for such losses in coastal wetlands is tremendous demand for land (Jiang et al., 2015; Kingsford et al., 2016). The major threat to coastal wetlands is the transformation of coastal ecosystems, which is the result of urbanization, which leads to significant loss and change of habitat (Gallant, 2015; Xu et al., 2016). Wetland loss is an important problem in local communities as well as for many wetland species that depend on wetlands (Orimoloye et al., 2018). 
Table 5. Patch numbers of LULC categories according to patch area coverages

\begin{tabular}{|c|c|c|c|c|c|c|c|c|c|c|c|c|c|c|c|}
\hline & & \multicolumn{14}{|c|}{ Years } \\
\hline & & \multicolumn{7}{|c|}{1996} & \multicolumn{7}{|c|}{2018} \\
\hline & & \multicolumn{14}{|c|}{ Patch size category (ha) } \\
\hline & & $0-0.9$ & $1-4.9$ & $5-9.9$ & $10-49.9$ & $\begin{array}{l}50 \text { or } \\
\text { more }\end{array}$ & $\begin{array}{c}\text { No. of patch } \\
\text { (total) }\end{array}$ & $\begin{array}{l}\text { Av. patch } \\
\text { area (ha) }\end{array}$ & $0-0.9$ & $1-4.9$ & $5-9.9$ & $10-49.9$ & $\begin{array}{l}50 \text { or } \\
\text { more }\end{array}$ & $\begin{array}{c}\text { No. of patch } \\
\text { (total) }\end{array}$ & $\begin{array}{l}\text { Av. patch } \\
\text { area (ha) }\end{array}$ \\
\hline \multirow{2}{*}{1} & No. of patch & 197 & 2 & - & - & - & 199 & & 244 & 3 & - & - & - & 247 & \\
\hline & Patch area (ha) & 16.31 & 2.99 & - & - & - & & 0.10 & 21.51 & 4.27 & - & - & - & & 0.10 \\
\hline \multirow{2}{*}{2} & No. of patch & - & - & 1 & - & - & 1 & & 1 & 1 & - & - & - & 2 & \\
\hline & Patch area (ha) & - & - & 7.39 & - & - & & 7.39 & 0.18 & 4.37 & - & - & - & & 2.28 \\
\hline \multirow{2}{*}{3} & No. of patch & 15 & 1 & - & - & - & 16 & & 27 & 8 & - & - & - & 35 & \\
\hline & Patch area (ha) & 3.18 & 3.11 & - & - & - & & 0.39 & 7.63 & 13.75 & - & - & - & & 0.61 \\
\hline \multirow{2}{*}{4} & No. of patch & 3 & 2 & - & - & - & 5 & & 3 & 2 & - & - & - & 5 & \\
\hline & Patch area (ha) & 2.16 & 3.07 & - & - & - & & 1.05 & 2.21 & 3.02 & - & - & - & & 1.05 \\
\hline \multirow{2}{*}{5} & No. of patch & 8 & 2 & - & - & - & 10 & & 5 & - & - & - & - & 5 & \\
\hline & Patch area (ha) & 2.42 & 2.82 & - & - & - & & 0.52 & 1.12 & - & - & - & - & & 0.22 \\
\hline \multirow{2}{*}{6} & No. of patch & 21 & 8 & - & 3 & - & 32 & & 20 & 8 & - & - & - & 28 & \\
\hline & Patch area (ha) & 7.14 & 19.29 & - & 45.70 & - & & 2.25 & 6.20 & 13.00 & - & - & - & & 0.69 \\
\hline \multirow{2}{*}{7} & No. of patch & 62 & 3 & - & - & - & 65 & & 65 & 9 & 1 & - & 1 & 76 & \\
\hline & Patch area (ha) & 10.88 & 3.57 & - & - & - & & 0.22 & 12.70 & 17.38 & 7.83 & - & 51.97 & & 1.18 \\
\hline \multirow{2}{*}{8} & No. of patch & - & - & - & - & - & - & & - & 1 & - & - & - & 1 & \\
\hline & Patch area (ha) & - & - & - & - & - & & - & - & 0.87 & - & - & - & & 0.87 \\
\hline
\end{tabular}


Table 5. cont. Patch numbers of LULC categories according to patch area coverages

\begin{tabular}{|c|c|c|c|c|c|c|c|c|c|c|c|c|c|c|c|}
\hline & & \multicolumn{14}{|c|}{ Years } \\
\hline & & \multicolumn{7}{|c|}{1996} & \multicolumn{7}{|c|}{2018} \\
\hline & & \multicolumn{14}{|c|}{ Patch size category (ha) } \\
\hline & & $0-0.9$ & $1-4.9$ & $5-9.9$ & $10-49.9$ & $\begin{array}{l}50 \text { or } \\
\text { more }\end{array}$ & $\begin{array}{c}\text { No. of patch } \\
\text { (total) }\end{array}$ & $\begin{array}{l}\text { Av. patch } \\
\text { area (ha) }\end{array}$ & $0-0.9$ & $1-4.9$ & $5-9.9$ & $10-49.9$ & $\begin{array}{l}50 \text { or } \\
\text { more }\end{array}$ & $\begin{array}{c}\text { No. of patch } \\
\text { (total) }\end{array}$ & $\begin{array}{l}\text { Av. patch } \\
\text { area (ha) }\end{array}$ \\
\hline \multirow{2}{*}{9} & No. of patch & 86 & 16 & 2 & - & - & 104 & & 124 & 12 & - & - & - & 136 & \\
\hline & Patch area (ha) & 28.39 & 26.40 & 13.79 & - & - & & 0.66 & 33.22 & 25.48 & - & - & - & & 0.43 \\
\hline \multirow{2}{*}{10} & No. of patch & 228 & 18 & - & - & - & 246 & & 209 & 13 & - & - & - & 222 & \\
\hline & Patch area (ha) & 57.64 & 24.97 & - & - & - & & 0.34 & 55.99 & 17.64 & - & - & - & & 0.33 \\
\hline \multirow{2}{*}{11} & No. of patch & 39 & 23 & - & - & - & 62 & & 53 & 18 & - & - & - & 71 & \\
\hline & Patch area (ha) & 19.78 & 38.47 & - & - & - & & 0.94 & 19.71 & 31.04 & - & - & - & & 0.71 \\
\hline \multirow{2}{*}{12} & No. of patch & 2 & - & - & - & - & 2 & & 4 & - & - & - & - & 4 & \\
\hline & Patch area (ha) & 0.87 & - & - & - & - & & 0.44 & 1.82 & - & - & - & - & & 0.46 \\
\hline \multirow{2}{*}{13} & No. of patch & 44 & 3 & - & - & - & 47 & & 39 & 14 & - & - & - & 53 & \\
\hline & Patch area (ha) & 11.59 & 4.89 & - & - & - & & 0.35 & 15.44 & 28.63 & - & - & - & & 0.83 \\
\hline \multirow{2}{*}{14} & No. of patch & 10 & - & 1 & 1 & - & 12 & & 4 & - & 1 & - & - & 5 & \\
\hline & Patch area (ha) & 1.47 & - & 6.37 & 12.31 & - & & 1.68 & 0.74 & - & 6.80 & - & - & & 1.51 \\
\hline \multirow{2}{*}{15} & No. of patch & 8 & - & - & - & - & 8 & & 5 & - & - & - & - & 5 & \\
\hline & Patch area (ha) & 1.31 & - & - & - & - & & 0.16 & 0.52 & - & - & - & - & & 0.10 \\
\hline \multirow{2}{*}{16} & No. of patch & - & - & - & - & 1 & 1 & & 2 & - & - & - & 1 & 3 & \\
\hline & Patch area (ha) & - & - & - & - & 88.97 & & 88.97 & 0.22 & - & - & - & 62 & & 20.74 \\
\hline
\end{tabular}

LULC = land use and land cover. 1. discontinuous urban fabric; 2. industrial or commercial units; 3. road and rail networks and associated land; 4. port areas; 5. dump sites; 6. construction sites; 7. green urban areas; 8. sport and leisure facilities; 9. non-irrigated arable land; 10. permanently irrigated land; 11. fruit trees and berry plantations; 12 . sclerophyllous vegetation; 13 . sparsely vegetated areas; 14 . inland marshes; 15 . water courses; 16. coastal lagoons 

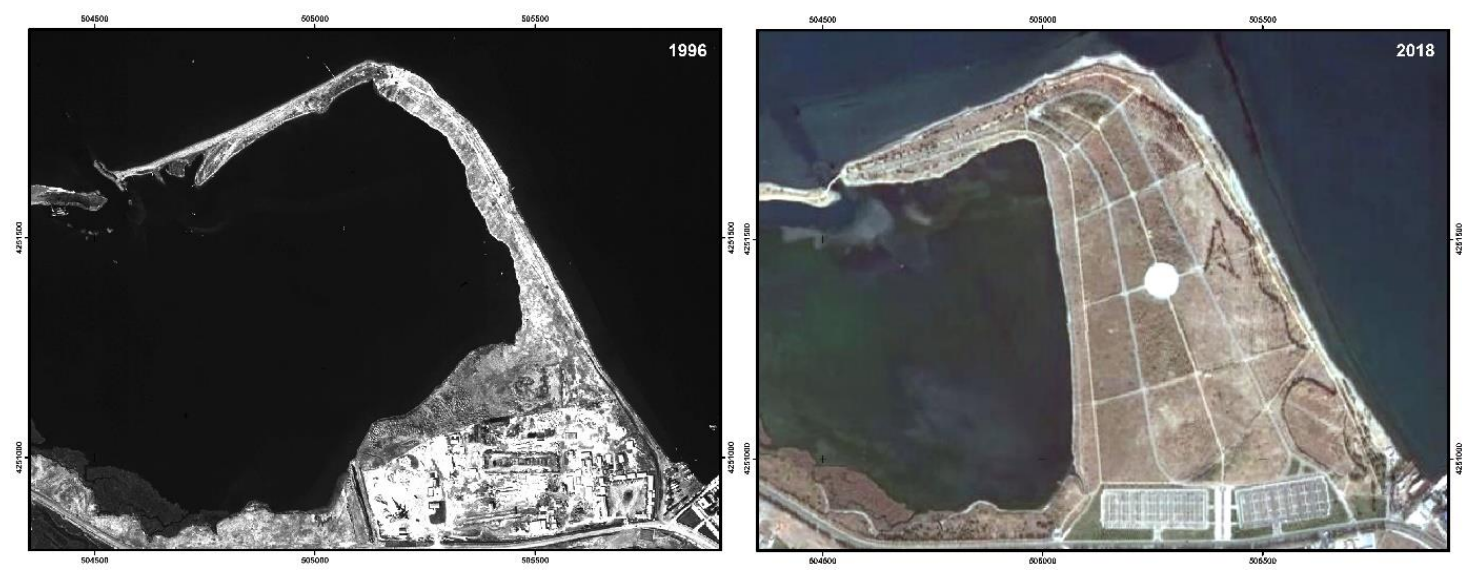

Figure 6. Conversion of coastal lagoons in Inciralti

In addition to the change/conversion of the LULC classes, patch numbers and patch area sizes reveal the state of agricultural areas and wetlands in Inciralti. The increase in the patch number with the smallest area size (0-0.9 ha) indicates that the discontinuous urban fabric spread throughout Inciralti (as agricultural enterprises and villas). This result is supported by the view that if the number of small patches increases, fragmentation also increases (Lasanta et al., 2015)

The extension of the discontinuous urban fabric to the west caused fragmentation of the agricultural areas particularly by creating pressure on these areas. The result of this study coincides with the view that the spreading construction areas occupy agricultural areas and divide large agricultural patches into small ones (Liang et al., 2015). A study assessing LULC changes in Romania found that serious fragmentation of agricultural land caused significantly decreasing in the quality and quantity of land use (Popovici et al., 2013).

When the changes in the total patch number, the number of patches with small sizes, the average patch area and total area size of the agricultural areas together, it is observed that these areas were subjected to conversion by severe fragmentation.

The changes in the total area size, total patch number and average patch area and the number of patches with small sizes of wetlands indicates severe fragmentation and rapid conversion. Similarly, on the analysis of LULC changes; it is stated that the total class area, the number of patches, the average patch size and the largest patch size provide information about the fragmentation of the landscape (Grecchi et al., 2014).

The results of the study are important in terms of revealing the LULC changes, conversions and fragmentations in Inciralti in detailed. The results of the study are important to reveal the LULC changes, conversions, and fragmentations in Inciralti in detailed. The results of the study are also important in terms of understanding the agricultural potential and ecological value of the area and contribute to the development of social awareness for the preservation of the agricultural and wetland character of Inciralti.

\section{Conclusion}

Changes, conversions, and fragmentations of LULCs in the study area over the years have caused changes in the existing natural and cultural structure of Inciralti. For this 
reason, ecological importance of coastal areas should be prioritized (Rahman et al., 2017). The wetland characteristics of Inciralti can be protected by preventing the filling works for obtaining green urban areas and making wetland restoration.

Small patches of agricultural areas should be combined in order to reduce the severity of fragmentation.

Planning and management studies for Inciralti should focus on the protection of agricultural lands and wetlands as well as physical and economic development. An ecosystem-based conservation approach can be supported in areas accommodating different uses that meet the needs of multiple bird species/communities (Ma, et al., 2010). Appropriate land management is a way to avoid the negative effects of unplanned development (Rahman et al., 2017). To achieve this, planning and management studies should take into account landscape dynamics and LULC changes/conversions.

In future studies, the effects of temporal changes, conversions and fragmentations of the LULC on the agricultural product model, flora and fauna diversity, and people's mental health can be examined. Future studies provide quantified metrics for their study areas such as percent impervious surfaces, road density, and human population density. The effects of the intense demands of landowners for the development of agricultural land, the most important problem threatening Inciralti, on LULC changes can be analyzed. The pressure of green space demands on agricultural areas and wetlands can also be evaluated.

\section{REFERENCES}

[1] Balado, J., Arias, P., Diaz-Vilarino, L., Gonzalez de Santos, L. M. (2018): Automatic CORINE land cover classification from airborne LIDAR data. - Procedia Comput Sci 126: 186-194.

[2] Cole, B., Smith, G., Balzter, H. (2018): Acceleration and fragmentation of CORINE land cover changes in the United Kingdom from 2006-2012 detected by Copernicus IMAGE2012 satellite data. - International Journal of Applied Earth Observation and Geoinformation 73: 107-122.

[3] Dzieszko, P. (2014): Land-cover modelling using CORINE land cover data and multilayer perceptron. - Quaestiones Geographicae 33(1): 5-22.

[4] Esbah, H. (2004): Agricultural land loss due to urbanization. - Proceedings of AgroEnvirons, October 20-24, Udine, Italy, pp. 231-238.

[5] Fan, C., Myint, S. (2014): A comparison of spatial auto correlation indices and landscape metrics in measuring urban landscape fragmentation. - Landscape and Urban Planning 121: 117-128.

[6] Fan, X. C., Zhao, L. L. (2019): Land use changes and its driving factors: a case study in Nanping City, China. - Applied Ecology and Environmental Research 17(2): 3709-3721.

[7] Fonji, S. F., Taff, G. N. (2014): Using satellite data to monitor land-use land-cover change in North-eastern Latvia. - SpringerPlus 3: 61.

[8] Gallant, A. L. (2015): The Challenges of remote monitoring of wetlands. - Remote Sensing 7(8): 10938-10950.

[9] Goudie, A., Viles, H. (1997): The Earth Transformed: An Introduction to Human Impacts on the Environment. - Wiley-Blackwell, Oxford.

[10] Grecchi, R. C., Gwyn, Q. H. J., Bénié, G. B., Formaggio, A. R., Fahl, F. C. (2014): Land use and land cover changes in the Brazilian Cerrado: a multidisciplinary approach to assess the impacts of agricultural expansion. - Applied Geography 55: 300-312. 
[11] Hobbs, N. T., Schimel, D. S., Owensby, C. E., Ojima, D. S. (1991): Fire and grazing in the tallgrass prairie: contingent effects on nitrogen budgets. - Ecology 72(4): 1374-1382.

[12] Jiang, T. T., Pan, J. F., Pu, X. M., Wang, B., Pan, J. J. (2015): Current status of coastal wetlands in China: degradation, restoration, and future management. - Estuarine, Coastal and Shelf Science 164: 265-275.

[13] Kingsford, R. T., Basset, A., Jackson, L. (2016): Wetlands: conservation's poor cousins. - Aquatic Conservation 26(5): 892-916.

[14] Li, S. H., Peng, S. Y., Jin, B. X., Zhou, J. S., Li, Y. X. (2019): Scenario simulation of land use/cover change in Fuxian Lake basin based on conversion of land use and its effects at small region extent model, Yunnan province, China. - Applied Ecology and Environmental Research 17(4): 8895-8914.

[15] Kara, B., Esbah, H., Deniz, B. (2013): Monitoring and analyzing land use/land cover changes in a developing coastal town: a case study of Kusadasi, Turkey. - Journal of Coastal Research 29(6): 1361-1372.

[16] Kesgin, B., Nurlu, E. (2009): Land cover changes on the coastal zone of Candarli Bay, Turkey using remotely sensed data. - Environmental Monitoring and Assessment 157(14): 89-96.

[17] Kilic, S., Evrendilek, F., Senol, S., Celik, I. (2005): Developing a suitability index for land uses and agricultural land covers: a case study in Turkey. - Environmental Monitoring and Assessment 102(1-3): 323-335.

[18] Lasanta, T., Nadal-Romero, E., Arnáez, J. (2015): Managing abandoned farmland to control the impact of re-vegetation on the environment. The state of the art in Europe. Environmental Science \& Policy 52: 99-109.

[19] Liang, C., Penghui, J., Chen, W., Li, M., Wang, L., Gong, Y., Pian, Y., Xia, N., Duan, Y., Huang, Q. (2015): Farmland protection policies and rapid urbanization in China: a case study for Changzhou City. - Land Use Policy 48: 552-566.

[20] Lopez E., Bocco, G., Mendoza, M., Duhau, E. (2001): Predicting land cover and land use change in the urban fringe: a case in Morelia city, Mexico. - Landscape and Urban Planning 55(4): 271-285.

[21] Ma, Z., Cai, Y., Li, B., Chen, J. (2010): Managing wetland habitats for waterbirds: an international perspective. - Wetlands 30(1): 15-27.

[22] Maynard, L., Wilcox, D. A. (1997): Coastal Wetlands: State of the Lakes Ecosystem Conference 1996 (SOLEC 96) - Background Paper, Ontario.

[23] Moulton, D. W., Jacob, J. S. (2000): Texas Coastal Wetland Guidebook. - Texas Sea Grant Publication, Texas.

[24] Nuthammachot, N., Stratoulias, D. (2019): Fusion of Sentinel-1A and Landsat-8 images for improving land use/land cover classification in Songkla province, Thailand. - Applied Ecology and Environmental Research 17(2): 3123-3135.

[25] Orimoloye, I. R., Kalumba, A. M., Mazinyo, S. P., Nel, W. (2018): Geospatial analysis of wetland dynamics: wetland depletion and biodiversity conservation of Isimangaliso Wetland, South Africa. - Journal of King Saud University-Science. https://doi.org/10.1016/j.jksus.2018.03.004.

[26] Petrişor, A. I., Grigorovschi, M., Meiţă, V., Simion-Melinte, C. P. (2014): Long-term environmental changes analysis using CORINE data. - Environmental Engineering and Management Journal 13(4): 847-860.

[27] Popovici, E. A., Balteanu, D., Kucsicsa, G. (2013): Assessment of changes in land-use and land-cover pattern in Romania using CORINE land cover database. - Carpathian Journal of Earth and Environmental Sciences 8(4): 195-208.

[28] Price, B., Kienast, F., Seidl, I., Ginzler, C., Verburg, P. H., Bolliger, J. (2015): Future landscapes of Switzerland: risk areas for urbanisation and land abandonment. - Applied Geography 57: 32-41.

[29] Rahman, M. T. U., Tabassum, F., Rasheduzzaman, M. D., Saba, H., Sarkar, L., Ferdous, J., Uddin, S. Z., Zahedul Islam, A. Z. M. (2017): Temporal dynamics of land use/land 
cover change and its prediction using CA-ANN model for southwestern coastal Bangladesh. - Environmental Monitoring and Assessment 189: 565.

[30] Royer, A., Charbonneau, L., Bonn, F. (1988): Urbanization and Landsat MSS albedo change in the Windsor-Quebec corridor since 1972. - International Journal of Remote Sensing 9(3): 555-566.

[31] Rujoiu-Mare, M. R., Mihai, B. A. (2016): Mapping land cover using remote sensing data and GIS techniques: a case study of Prahova Subcarpathians. - Procedia Environmental Sciences 32: 244-255.

[32] Sanders, R. (2006): Protection of Agricultural Land from Urban Development - State Planning Policy 1/92. - Natural Resources and Water, Integrated Resource Management, Queensland Government, Australia.

[33] Serdar, S., Lök, A., Kırtık, A., Acarlı, S., Küçükdermenci, A., Güler, M., Yiğitkurt, S. (2010): Comparison of gonadal development of carpet shell clam (Tapes decussatus, Linnaeus 1758) in inside and outside of Çakalburnu lagoon, Izmir bay - Turkish Journal of Fisheries and Aquatic Sciences 10: 395-401.

[34] Sevil, Ş. (2010): Çakalburnu dalyanı (Cakalbunu lagoon) - Ekoloji Magazin 27.

[35] Turner II, B. L. (1989): The Human Causes of Global Environmental Change. - In: DeFries, R. S., Malone, T. (eds.) Global Change and Our Common Future: Papers from a Forum. National Academy Press, Washington, DC, pp. 90-99.

[36] Valdez, V. C., Ruiz-Luna, A., Berlanga-Robles, C. A. (2016): Effects of land use changes on ecosystem services value provided by coastal wetlands: recent and future landscape scenarios. - Journal of Coastal Zone Management 19(1): 418.

[37] Wang, Z., Zhang, B., Zhang, S., Li, X., Liu, D., Song, K., Li, J., Li, F., Duan, H. (2006): Changes of land use and of ecosystem service values in Sanjiang plain Northeast China. Environmental Monitoring and Assessment 112(1-3): 69-91.

[38] Xu, C., Pu, L., Zhu, M., Li, J., Chen, X., Wang, X., Xie, X. (2016): Ecological security and ecosystem services in response to land use change in the coastal area of Jiangsu, China. - Sustainability 8(8): 1-24.

[39] Zhang, J., Ma, K., Fu, B. (2010): Wetland loss under the impact of agricultural development in the Sanjiang Plain, NE China. - Environmental Monitoring and Assessment 166(1-4): 139-148. 